\title{
Using Electronic Business Simulation Games to Enhance Students' Learning at Palestine Polytechnic University: An Experimental Study
}

\author{
Nancy Alrajei and Diana Hassouneh
}

\begin{abstract}
Traditional education systems don't keep up with the requirements of today's businesses. As a result, business graduates find gaps between theory and practice, and between knowledge and skill. To eliminate these gaps, educational games are used to provide students with skills that can be used in any business environment to help them avoid common mistakes and be more effective at business development. Educational games and simulations are experiential exercises that take students to another level of learning where they apply their knowledge, skills, and strategies in the execution of their assigned roles. This paper presents and analyzes the use of an electronic business simulation platform (Simformer) where students had to manage huge virtual companies to optimize all business processes, increase profitability and enter new markets. The actions of the students were supervised by game moderators.
\end{abstract}

Index Terms - Business Games, Simulation, Palestine Polytechnic University, Simformer

\section{INTRODUCTION}

Today, technology can open new doors toward more development in all field. The role of technology in business world is obvious and inevitable. In this way, simulation games can be utilized in business to help the educators in business colleges in order to teach the students how to manage an enterprise.

"You learn more about a person in an hour of play than in a year of conversation". This Plato's saying of learning from games is truly captured when games are employed as an educational tool. In the last decade, many business schools have been demanding major changes in the way of teaching: use of real-world applications, cases, spreadsheets, and collaboration with other functional areas, which can be described as "Learning by Doing".

These games can simulate the real situations which the students will face to them in future. So the students will find this opportunity to manage an enterprise in virtual world and this will prepare them to solve solutions in real life in future. They can use all principals and theories of business in practice. Thus, this new technology can enhance the student's abilities and skills to manage a business.

\footnotetext{
*Nancy Alriji and Diana Hassouneh both are with the Department of Administrative Science and Informatics Palestine Polytechnic University, Hebron, Palestine .
}

Simformer is one the online business game that Palestine Polytechnic University used for this experiment. Where students established and run their virtual businesses. Running the business the competing with others made students review and use a lot of business concepts that they learn in class.

After the game was over, students filled out two questionnaires regarding this experiment to figure out what impact it has on students'skills, and what will motivate them to try it again.

The paper is organized as follows: Section 2 previous work is briefly summarized. In Section 3, we explain Simfomer business game simulations. In Section 4, we explain the experiment 4. In Section 5 we conclude our study.

\section{PREVIOUS WORK}

The history of business simulation games began in China in the year $3000 \mathrm{BC}$ where they have been used as board and war games. Wolfe (1993) dates the modern business simulation game to year 1956 when the first widely known business simulation game, under the name Top Manage- ment Decision Simulation, was developed (Meier et al., 1969). That game was the first practical and successful business simulation. From that time, as Kibbee has reported, the number of busi- ness simulation games grew rapidly, and, already in year 1961, it was estimated that there were existing over 100 business games and that over 30,000 managers have played at least one business game (Kibbee et al., 1961).

There exists quite extensive literature exploring learning in a simulated environment. Many studies are questioning the validity of the business simulations for education purposes (Greenlaw and Wyman, 1973, Wolfe, 1985). Thorngate and Carroll (1987) found that luck or success in play- ing the simulation game correlated with the number of players, in defining a winner, as well as the structure of the contest have no significant difference regarding the chances that the best person would win. In the report they have implicated that learning and performance are not relat- ed. Keys and Wolfe (1990), claim that simulations are internally valid for a strategic management course, while Wolfe and Roberts (1993) state that business simulation games have external valid- ity in predicting future career success of players

Watson (1981) states that business simulation games have been used in business schools since 1957. A survey conducted in 1962 reported that $71.1 \%$ of 107 schools included into survey, were using simulation games in at least one course 
(Dale and Klasson 1962). Faria (1987) reported that

\section{SIMFORMER}

Simformer is An online business game that shows the realities of crisis management. The participants will have to make the right decision in a short period of time to lead their companies out of financial difficulties.

The participants will have to manage a huge virtual company, which is faced with serious financial difficulties. The goal of the business game to optimize all business processes, increase company's profitability and enter new markets. The actions of the participants are supervised by game moderators.

During the course the participants will be involved in these activities and business processes:

- Strategic Management

- Business planning.

- Business expansion

- Supply chain management.

- HR management.

- Sales.

The course is primarily focused on the development of such skills as:

- Decision making.

- Analytical thinking.

- Stress- resistance.

- Out-of-the-box thinking.

- Strategic and systematic thinking.

IV. BUSINESS GAME: CORPORATION IN DISTRESS

One of the business games is Corporation is Distress, that is contains of 7 modules:

Introduction. Game objectives and its dynamics.

Module 2: The basics of retail trade management.

- Theory: Retail sales and operations: pricing policy, purchasing, supply management.

- Tasks: Choose the optimal price product quality and store location. Manage inventory and sales.

- Practice in business simulation: Manage a product range, purchasing, inventory, and pricing policy.

- Assignments in business simulation: Improve the current chain of retail stores and make them profitable: price, product quality, inventory, and delivery.

Module 3: Retail subdivision: size and employees.

- Theory: Compensation plan, staff qualification and efficiency.

- Tasks: Choose the optimal size of the store and the compensation plan.

- Practice in business simulation: HR manager functions, moving the subdivision to another location, up/downsizing.

- Assignments in business simulation: Optimize the size of retail subdivisions and select the compensation plan. Make sure unprofitable stores are profitable again.
Module 4: Advertising campaigns and business efficiency.

- Theory: Advertising channel planning, target audience, advertising campaign efficiency.

- Tasks: Maximize advertising campaign efficiency.

- Practice in business simulation: The functionality of advertising campaigns.

- Assignments in business simulation: Achieve $100 \%$ in advertising campaign efficiency. Support operating activities, maximize subdivisions' revenues.

Module 5: Restaurant management.

- Theory: Restaurant development and management.

- Practice in business simulation: Key business functions in restaurant management.

- Assignments in business simulation: Increase restaurant net profit by at least $25 \%$. Maximize the profitability of retail subdivisions.

Module 6: Factory performance.

- Theory: Factory management.

- Practice in business simulation: Key business functions in factory management.

- Assignments in business simulation: Increase factory net profit by at least $25 \%$. Maximize the profitability of the restaurant and retail subdivisions.

Module 7: Expansion into new markets.

- Theory: Strategies in geographical and product expansion.

- Practice in business simulation: Market analysis, find a market niche, open new subdivisions.

- Assignment in business simulation: Open at least 2 retail subdivisions. Maximize the profitability of existing subdivisions.

Module 8: Business growth and optimization.

- Assignment in business simulation. Maximize the profitability of existing subdivisions.

\section{EXPERIMENT}

Palestine Polytechnic University, Collage of administrative science and Informatics conducted an academic competition using one of Simformer business game " Corporation in Distress" which is an online business game which focuses on developing students' strategic and analytical thinking skills. In addition to that, one of the main focuses of the game was team work: the students made all their decisions together. Due to that, the participants were able to develop their collaborative skills, provide help to others and ask for help, and put the interests of the whole team first. The team work during the game revealed the communication and leadership skills of each participant.

The competition had 150 students from the College of Administrative Sciences and Informatics. All majors had the chance to participate: Business Administrative, Economics, Accounting, E-marketing and Information Systems.

The participants were divided into 30 teams. Every team was responsible for building and managing a virtual company for the entire game period. Every team got access to Simformer 
virtual business environment. The game was moderated by a team collage staff, and supervised online by Simfomer member via skype.

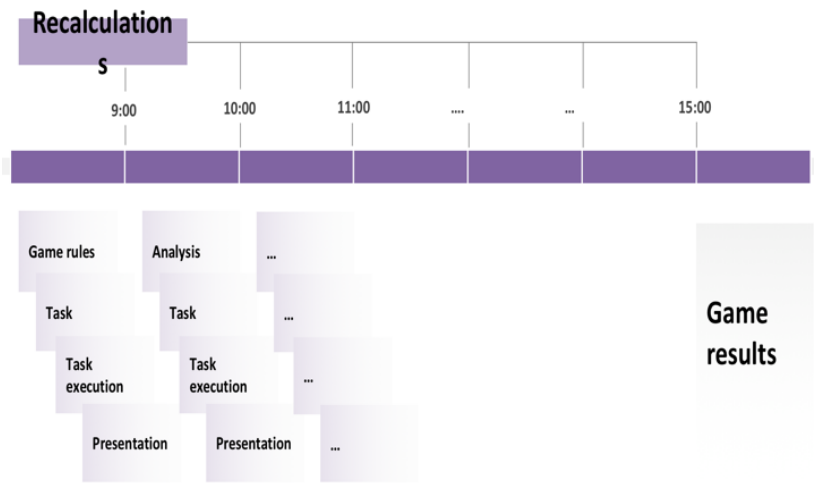

Fig. 1 Game timeline

The participants of each team had to manage a huge corporation, which was facing financial difficulties

The corporation consisted of various subdivisions responsible for manufacturing and sales. The subdivisions were connected with each other as well as the external suppliers, contractors, and customers. The goal of the game was to lead the corporation out of crisis and stabilize its processes.

The entire game took 7 hours, the timeline for the game is shown in Figure 1.

In every hour Students were given the game rules by game moderators, then they were given a task to perform, execute the task electronically, by the end of the hour ,Simfomer will do an automatic recalculation on their site which means saving the changes students made during this task and the outcome of this task on the company will be shown. The winner for

Students were given an introduction. Which was the essence of a business game, companies' subdivisions and their indicators, criteria for winning

\section{1- Task 1 :}

a. Managing a retail business

b. Task details : to optimize the sales and supply in the stores

\section{2- Task 2:}

- Introduction of marketing and advertising. The basics of managing the size and location of a retail business, Human Resources management.

- Task details:

a. To sustain current operations.

b. To launch an advertising campaign. To optimize stores' size, location and staff.

\section{3- Task 3:}

- Managing a restaurant, Managing a factory.

- Task details:

a. To sustain current retail operations. To increase restaurant's and factory's profitability

\section{4- Task 4:}

- Retail, entering new markets: the choice of location and production line.

- Task details:

a. To sustain operating activity.

b. To increase overall profitability by opening new subdivisions.

Motor bikes auction, sugar: $\mathrm{Q}=15$, auction bidding. Forecast sales of sausages (1 unit).

\section{5- Task 5}

- Optimization and business expansion.

- Task details:

a. To sustain operating activity.

b. To optimize the business and increase its overall productivity.

\section{6- Task 6}

- Optimization and business expansion.

- Task details:

a. To sustain operating activity.

b. To optimize the business and increase its overall productivity.

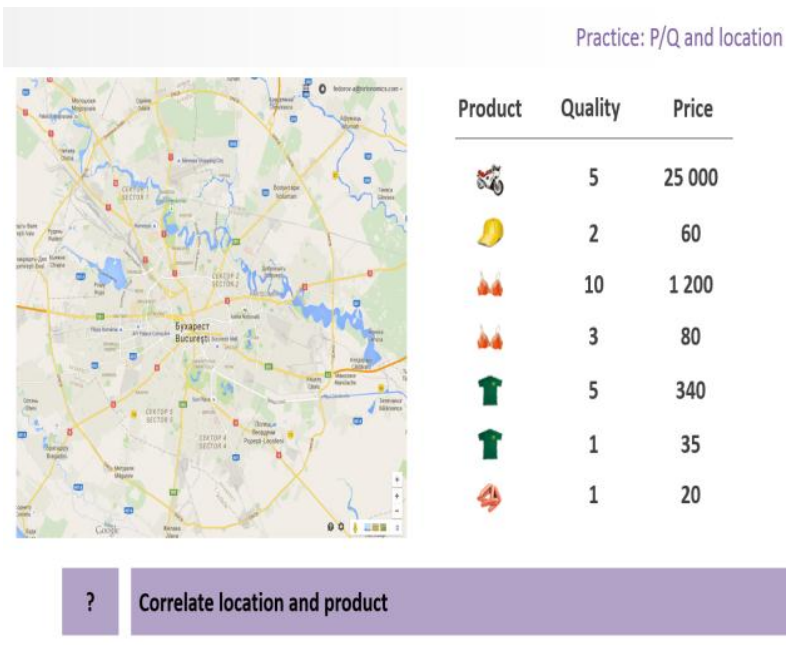

Fig. 2. Simulation screen that shows the correlation between Price, Quality, Location

\section{RESUlTS}

A questionnaire that was filled out by 96 Students with questions about how much they think the game enhanced their skills. Another simple questionnaire was distributed, 72 students filled out the questionnaire to get the participants opinion about the game, and what would motivate them to participate again in such games.

Our results show that using business games simulation in teaching and learning could clearly enhance student skills, and motivation for learning. Our student were highly satisfied with this experience. Results are explained as the following:

\section{A. How the game enhanced the participants skills:}

We suggested a set of skills that this game might improve for students. To verify our premises, we asked the students how much do you think the game enhanced the following skills, remembering that 72 answered this survey:

1- Leadership skills, as in Figure 3. Showed that 35 think it is Excellently enhanced their leadership skills. In Addition to 19 others think it is "Good".

2- Risk Management Skills as in Figure 4, 35 students Think it is "Excellent", and 19 answered it is "Good".

3- Overall Managerial Skills as in Figure 5, About 30 student answered it is " Excellent", and "25 said it is 
"Good".

4- Experience Gained as in Figure 6, 28 students answered it is "Excellent", and 27 said it is "Good".

5- Communication skills as in Figure 7, 33 students answered it is "Excellent" and 28. Said it is "Good".

6- Decision Making Skills, 35 students answered it is "Excellent" and 23 said it is "Good".

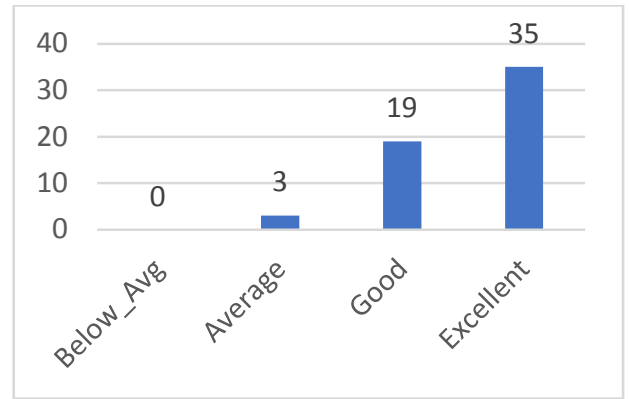

Fig. 3. Leadership Skills

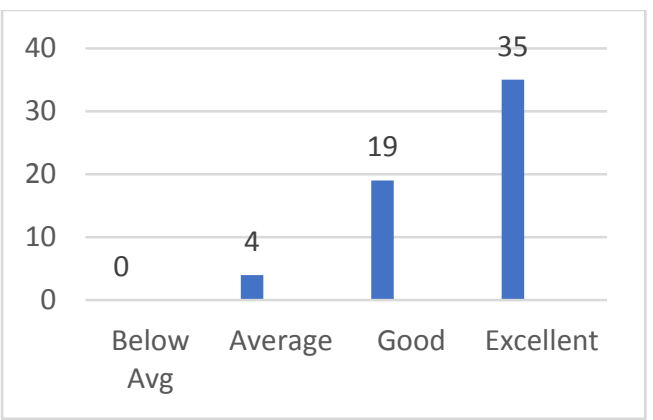

Fig. 4. Risk Management Skills

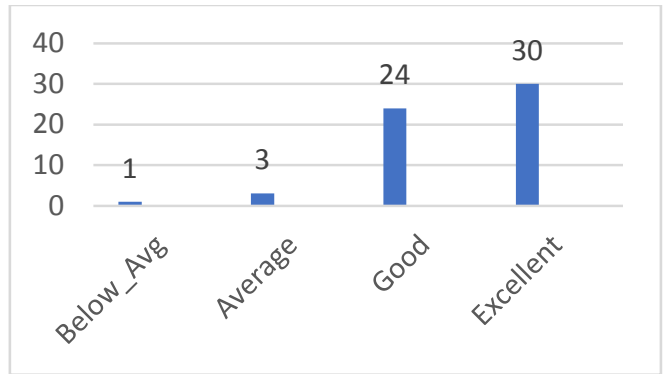

Fig 5. Overall Managerial Skills

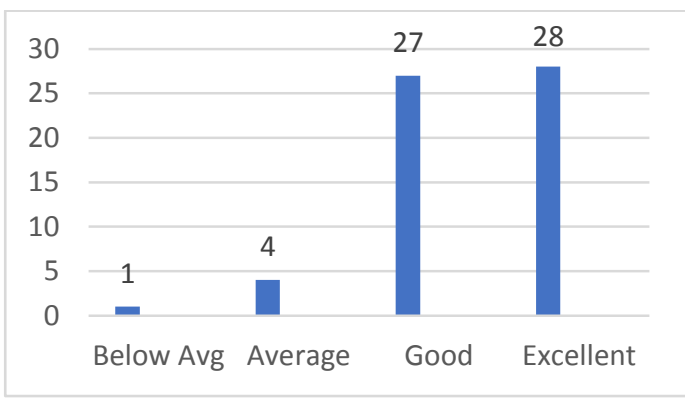

Fig. 6. Experience Gained

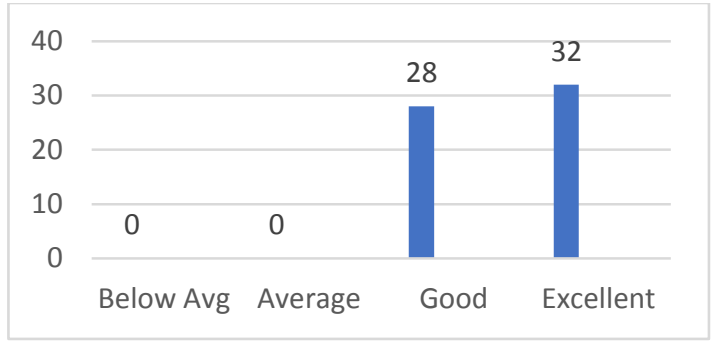

Fig. 7. Communication skills

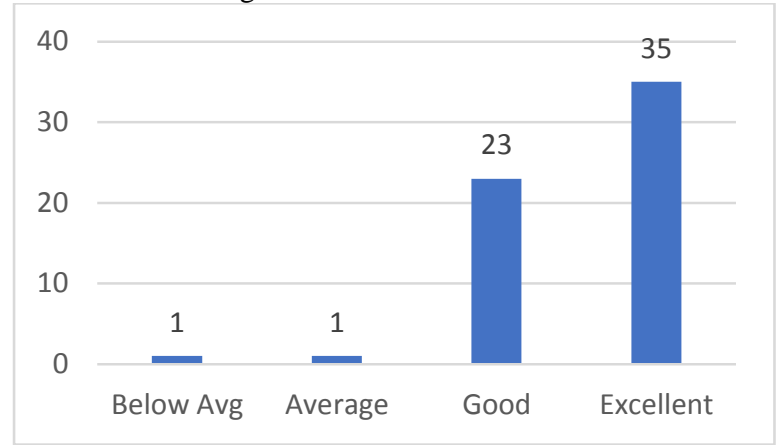

Fig. 8. Decision Making Skills

\section{MOTIVATION}

The Second part of the study was to evaluate their satisfaction of engaging in a business simulation game as a tool for learning where they can put theory into practice and use the knowledge they gained in school in real time situations. They worked in teams, where they had to communicate, think out loud, take risks, and make decisions.

The nature of this game made students feel that they run real life business, where they had to buy, sell, manufacture, market, expand business in other locations, and advertise. Which is generally speaking, they had to practice all business aspects in one game.

The results of a survey answered by 96 participants, show that students were highly satisfied by this experiment, and they were positively engaged during the entire time of the simulation game.

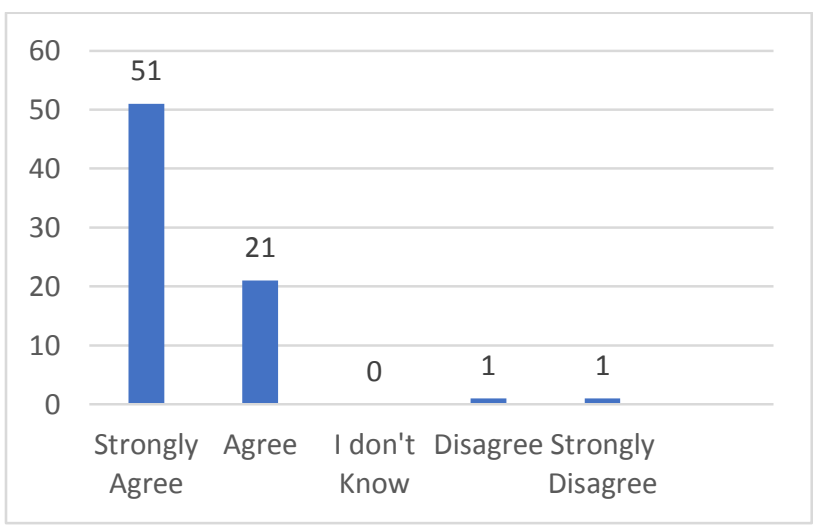

Fig. 9. Student Satisfaction with the experience

1- Student Satisfaction with the experience, as shown in Figure 9. The majority of student strongly agree that 
game was satisfactory to them, in terms of its benefits, challenges, and fun.

2- The majority of students agreed that they will participate again in the game if they had the chance to repeat the experience. Figure 10 shows that result.

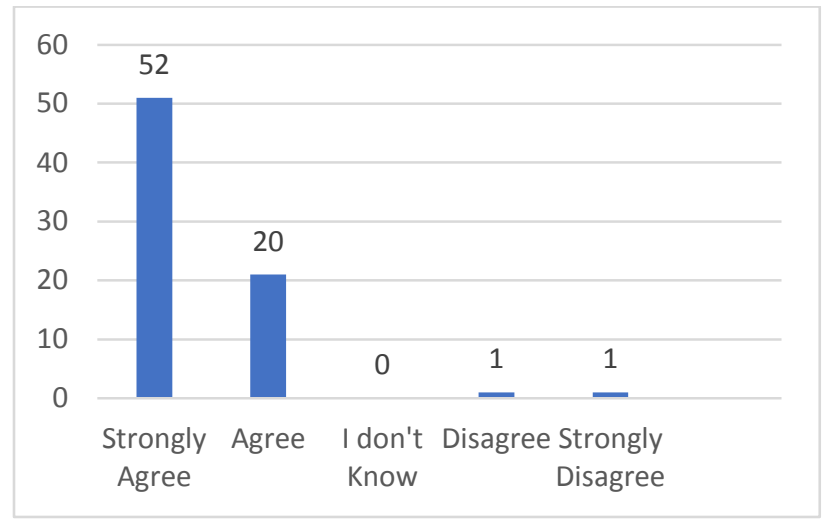

Fig10. Will participate again in the game

\section{FEEDBACK AND RECOMMENDATIONS}

In the same Questionnaire, students had the chance to express their opinion and give suggestions for future trials. We summarize those recommendations from students as the following:

1. Student Level: it suitable for students in their third, and fourth year of study, after they are done with most of the major courses in Business Administration.

2. Simulation preparation: students suggested that they needed time prior to the game get familiar with simulation environment. It is like any other electronic game, needs practice to achieve the most out of it.

3. Staff preparation: A lot of questions and queries regarding the sequence of the game came up from students, so the staff also should be also prepared to be able to help the students with their questions.

4. Team size: Students like to be in charge with their businesses, and with a big number of participants in each team, resulted in less time each students had to contribute. So they suggested a team of three students.

5. Simulation in curriculum: Students enjoyed the game that most suggestions came on "we want it in every course" which is a very positive indication on the success of this experience.

\section{CONCLUSION}

Electronic-based simulation games give students both repeated exposure to the decision-making environment and the opportunity to deal with a large amount of detailed information. While participating in a simulation game, students must work together to make decisions concerning a wide range of variables over a period of time in a competitive environment. This means that students must analyze detailed information, as in case studies, but they must do so in an environment filled with real stresses.

The results of this study do not mean that simulation games are considered to be more valuable than traditional lecturing, but it should be used as a complementary tool in the lab. Student learn theory knowledge using traditional lecturing format, then they should be exposed to practical simulation games where they can implement theory in practice.

Our results found that simulation games has huge impact on students skills such as decision making that showed the highest impact in the results.

Students were highly motived and engaged throughout the entire time of game, they agreed that they were satisfied with the experience and would like to participate again in same

Our recommendation is use electronic business games in teaching business administration courses and incorporate this new way of teaching along with traditional lecturing, students will be more involved and enjoy the process of learning

\section{REFERENCES}

[1] S. Chen, B. Mulgrew, and P. M. Grant, “A clustering technique for digital communications channel equalization using radial basis function networks," IEEE Trans. on Neural Networks, vol. 4, pp. 570-578, July 1993.

https://doi.org/10.1109/72.238312

[2] J. U. Duncombe, "Infrared navigation-Part I: An assessment of feasibility," IEEE Trans. Electron Devices, vol. ED-11, pp. 34-39, Jan. 1959.

[3] C. Y. Lin, M. Wu, J. A. Bloom, I. J. Cox, and M. Miller, "Rotation, scale, and translation resilient public watermarking for images," IEEE Trans. Image Process., vol. 10, no. 5, pp. 767-782, May 2001. https://doi.org/10.1109/83.918569

[4] A. Cichocki and R. Unbehaven, Neural Networks for Optimization and Signal Processing, 1st ed. Chichester, U.K.: Wiley, 1993, ch. 2, pp. 45-47.

[5] W.-K. Chen, Linear Networks and Systems, Belmont, CA: Wadsworth, 1993, pp. 123-135.

[6] H. Poor, An Introduction to Signal Detection and Estimation; New York: Springer-Verlag, 1985, ch. 4.

[7] R. A. Scholtz, "The Spread Spectrum Concept," in Multiple Access, N. Abramson, Ed. Piscataway, NJ: IEEE Press, 1993, ch. 3, pp. 121-123.

[8] G. O. Young, "Synthetic structure of industrial plastics," in Plastics, 2nd ed. vol. 3, J. Peters, Ed. New York: McGraw-Hill, 1964, pp. 15-64.

[9] M. B. Kasmani, "A Socio-linguistic Study of Vowel Harmony in Persian (Different Age Groups Use of Vowel Harmony Perspective," Internatio nal Proceedings of Economics Development and Research, ed. Chen Da n, pp. 359-366, vol. 26, Singapore: IACSIT Press, 2011.

[10] W. D. Doyle, "Magnetization reversal in films with biaxial anisotropy," in Proc. 1987 INTERMAG Conf., 1987, pp. 2.2-1-2.2-6.

[11] G. W. Juette and L. E. Zeffanella, "Radio noise currents n short sections on bundle conductors," presented at the IEEE Summer Power Meeting, Dallas, TX, June 22-27, 1990.

[12] J. Williams, "Narrow-band analyzer," Ph.D. dissertation, Dept. Elect. Eng., Harvard Univ., Cambridge, MA, 1993.

[13] N. Kawasaki, "Parametric study of thermal and chemical nonequilibrium nozzle flow," M.S. thesis, Dept. Electron. Eng., Osaka Univ., Osaka, Japan, 1993.

[14] J. P. Wilkinson, "Nonlinear resonant circuit devices," U.S. Patent 3624 12, July 16, 1990.

[15] Letter Symbols for Quantities, ANSI Standard Y10.5-1968.

[16] Transmission Systems for Communications, 3rd ed., Western Electric Co., Winston-Salem, NC, 1985, pp. 44-60.

[17] Motorola Semiconductor Data Manual, Motorola Semiconductor Products Inc., Phoenix, AZ, 1989.

[18] R. J. Vidmar. (August 1992). On the use of atmospheric plasmas as electromagnetic reflectors. IEEE Trans. Plasma Sci. [Online]. 21(3). pp. 876-880. http://www.halcyon.com/pub/journals/21ps03-vidmar 